IUCrJ

ISSN 2052-2525

PHYSICS|FELS

Received 17 September 2019

Accepted 3 February 2020

Edited by $\mathrm{H}$. Chapman, DESY/Universität Hamburg, Germany

₹ These authors contributed equally to this study

Keywords: X-ray diffraction; X-ray scattering; structure determination; single nanoparticles; crystalline defects; XFELs; angular correlations; stacking faults.

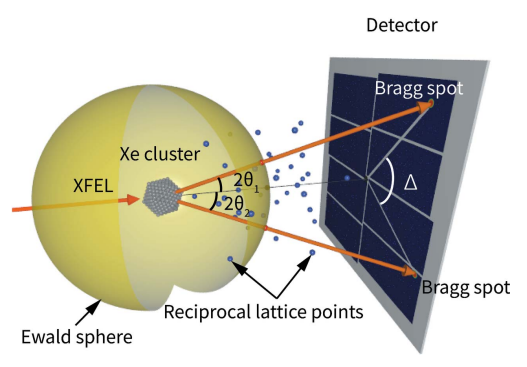

OPEN $\odot$ ACCESS

\section{Characterizing crystalline defects in single nanoparticles from angular correlations of single-shot diffracted X-rays}

\author{
Akinobu Niozu, ${ }^{\mathrm{a}, \mathrm{b}} \neq$ Yoshiaki Kumagai, ${ }^{\mathrm{c}, \mathrm{d}} \neq$ Toshiyuki Nishiyama, ${ }^{\mathrm{a}, \mathrm{b}}$ Hironobu \\ Fukuzawa, ${ }^{\mathrm{b}, \mathrm{c}}$ Koji Motomura, ${ }^{\mathrm{c}}$ Maximilian Bucher, ${ }^{\mathrm{d}}$ Kazuki Asa, ${ }^{\mathrm{a}, \mathrm{b}}$ Yuhiro Sato, ${ }^{\text {a,b }}$ \\ Yuta Ito, ${ }^{\mathrm{c}}$ Tsukasa Takanashi, ${ }^{\mathrm{c}}$ Daehyun You, ${ }^{\mathrm{c}}$ Taishi Ono, ${ }^{\mathrm{c}}$ Yiwen Li, ${ }^{\mathrm{c}}$ Edwin Kukk, \\ Catalin Miron, ${ }^{\mathrm{f}, \mathrm{g}}$ Liviu Neagu, ${ }^{\mathrm{g}, \mathrm{h}}$ Carlo Callegari, ${ }^{\mathrm{i}}$ Michele Di Fraia, ${ }^{,}$Giorgio Rossi, ${ }^{\mathrm{j}}$

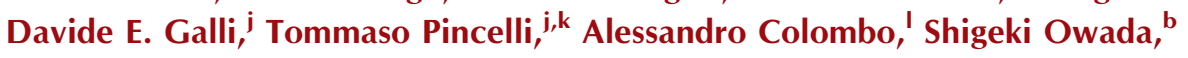 \\ Kensuke Tono, ${ }^{\mathrm{m}}$ Takashi Kameshima, $^{\mathrm{m}}$ Yasumasa Joti, ${ }^{\mathrm{m}}$ Tetsuo Katayama, $^{\mathrm{m}}$ Tadashi

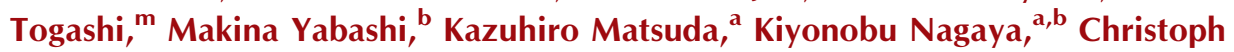 \\ Bostedt $^{\mathrm{d}, \mathrm{n}, \mathrm{o}}$ and Kiyoshi Ueda ${ }^{\mathrm{b}, \mathrm{c} *}$
}

a Department of Physics, Kyoto University, Kyoto 606-8502, Japan, ${ }^{\mathbf{b}}$ RIKEN SPring-8 Center, Sayo, Hyogo 679-5148, Japan, 'Institute of Multidisciplinary Research for Advanced Materials, Tohoku University, Sendai 980-8577, Japan, ${ }^{\mathbf{d} C h e m i c a l}$ Sciences and Engineering Division, Argonne National Laboratory, 9700 S. Cass Avenue, Argonne, IL 60439, USA, ${ }^{\mathbf{e}}$ Department of Physics and Astronomy, University of Turku, 20014 Turku, Finland, 'Université Paris-Saclay, CEA, CNRS, LIDYL, 91191, Gif-sur-Yvette, France, ${ }^{\mathbf{g}}$ Extreme Light Infrastructure - Nuclear Physics (ELI-NP), Horia Hulubei National Institute for Physics and Nuclear Engineering, 30 Reactorului Street, RO-077125 Magurele, Jud. Ilfov, Romania, ${ }^{\mathbf{h}}$ National Institute for Laser, Plasma and Radiation Physics, 409 Atomistilor PO Box MG-36, 077125 Magurele, Jud. Ilfov, Romania, 'Elettra - Sincrotrone Trieste S.C.p.A, 34149 Basovizza, Trieste, Italy, 'ंDepartment of Physics, Università degli

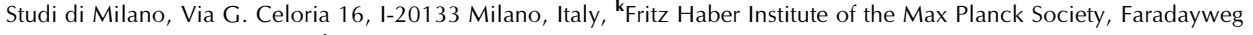
4-6, 14195 Berlin, Germany, 'Department of Physics, ETH Zürich, Stefano-Franscini-Platz 5, 8049 Zürich, Switzerland, mJapan Synchrotron Radiation Research Institute (JASRI), Sayo, Hyogo 679-5198, Japan, "Laboratory for Femtochemistry, Paul Scherrer Institute, CH-5232 Villigen PSI, Switzerland, and ${ }^{\mathbf{O} L U X S}$ Laboratory for Ultrafast X-ray Sciences, École Polytechnique Fédérale de Lausanne (EPFL), CH-1015 Lausanne, Switzerland. *Correspondence e-mail: kiyoshi.ueda@tohoku.ac.jp

Characterizing and controlling the uniformity of nanoparticles is crucial for their application in science and technology because crystalline defects in the nanoparticles strongly affect their unique properties. Recently, ultra-short and ultra-bright X-ray pulses provided by X-ray free-electron lasers (XFELs) opened up the possibility of structure determination of nanometre-scale matter with $\AA$ spatial resolution. However, it is often difficult to reconstruct the 3D structural information from single-shot X-ray diffraction patterns owing to the random orientation of the particles. This report proposes an analysis approach for characterizing defects in nanoparticles using wide-angle X-ray scattering (WAXS) data from free-flying single nanoparticles. The analysis method is based on the concept of correlated X-ray scattering, in which correlations of scattered X-ray are used to recover detailed structural information. WAXS experiments of xenon nanoparticles, or clusters, were conducted at an XFEL facility in Japan by using the SPring- 8 Angstrom compact free-electron laser (SACLA). Bragg spots in the recorded single-shot X-ray diffraction patterns showed clear angular correlations, which offered significant structural information on the nanoparticles. The experimental angular correlations were reproduced by numerical simulation in which kinematical theory of diffraction was combined with geometric calculations. We also explain the diffuse scattering intensity as being due to the stacking faults in the xenon clusters.

\section{Introduction}

Nanoparticles have been employed in a wide range of fields owing to their unique optical, electronic, magnetic, chemical and catalytic properties. These properties sensitively depend on various structural parameters such as size, shape and 
atomic structure (Brus, 1984; Halperin, 1986; Bawendi et al., 1990; Alivisatos, 1996; Burda et al., 2005). Therefore, characterizing and controlling the structural uniformity of the nanoparticles is an important issue for their application in science and technology. Several techniques have been used to characterize nanoparticles. Electron microscopy provides the structural information of single nanoparticles at atomic resolution; however, it cannot probe the internal structure of large nanoparticles (with thicknesses $>50 \mathrm{~nm}$ ) and often requires highly demanding procedures for sample preparation. Conventional powder X-ray diffraction is also widely used to characterize nanoparticles; however, the structural information is inevitably averaged by the random ensemble of the particles.

Bright femtosecond X-ray pulses from X-ray free-electron lasers (XFELs) (Emma et al., 2010 Ishikawa et al., 2012; Ko et al., 2017; Tschentscher et al., 2017; Milne et al., 2017) have provided novel opportunities to investigate the structure of nanoscale samples with $\AA$ resolution (Chapman et al., 2011; Aquila et al., 2015). In single-shot X-ray diffraction with XFELs, ultra-short X-ray pulses can avoid the major radiation-damage processes in the sample. Coherent-diffraction imaging with XFELs has enabled the structure determination of a wide variety of samples, including aerosol particles (Loh et al., 2012; Starodub et al., 2012), rare-gas clusters (Bostedt et al., 2010; Gorkhover et al., 2012), nanoparticles (Clark et al., 2013; Takahashi et al., 2013; Xu et al., 2014; Barke et al., 2015), superfluid quantum systems (Gomez et al., 2014) and biological objects (Chapman et al., 2011; Seibert et al., 2011; Boutet et al., 2012; Redecke et al., 2013; Kupitz et al., 2014; Hantke et al., 2014; Rose et al., 2018).

The analysis of single-shot diffraction data from single particles is inherently difficult owing to the random orientations of the particles in the scattering geometry. The diffraction pattern recorded on each shot is composed of scattering sensitive to only those 3D spatial frequencies which, in the representation of reciprocal space, lie on a certain 2D manifold corresponding to the Ewald sphere. Usually, the particle orientations must be determined to recover the entire 3D structural information from the diffraction patterns (Ekeberg et al., 2015). In serial femtosecond crystallography (SFX) of protein crystals, the crystal orientation is successfully determined for each diffraction pattern by indexing several Bragg spots that appear in that pattern. However, the procedure used in SFX is usually not applicable to the wide-angle X-ray scattering (WAXS) data of nanoparticles with short lattice parameters (a few Å's) because there are usually not enough Bragg spots in a pattern to obtain a reliable indexing solution.

An alternative approach to overcome the random particle orientations is a method called correlated X-ray scattering (CXS) (Kam, 1977, 1980) [also referred to as fluctuation X-ray scattering (Kam et al., 1981) or angular X-ray cross-correlation analysis (Kurta et al., 2017; Zaluzhnyy et al., 2019)]. CXS is an emerging method employed to recover the structure of an object from X-ray diffraction patterns of a random ensemble of identical objects. In CXS measurements with XFELs, the particles are frozen in space throughout the snapshot expo- sures of femtosecond X-ray pulses. The resulting diffraction patterns are anisotropic and contain intensity variations, which provide further structural information beyond diffraction patterns recorded with conventional sources, with exposure times that span many configurations of the fluctuating sample and which average away the short-exposure variations. Recently, several CXS studies at XFELs (Chen et al., 2012; Liu et al., 2013; Malmerberg et al., 2015; Kurta et al., 2017) have been carried out, which have demonstrated the structure reconstruction of nanoscale samples in solution or on a substrate. Mendez et al. applied CXS to a WAXS experiment with XFELs (Mendez et al., 2014, 2016) and demonstrated the effectiveness of CXS in the wide-angle region. They developed a robust analysis technique that could effectively extract intensity correlations from single-shot diffraction patterns and applied the method to the WAXS data of tens of thousands of gold nanoparticles in a solution. The analysis revealed evident angular correlation in the Debye-Scherrer rings, which offered information on crystal twinning in the particles.

In this report, we propose an application of CXS for characterizing crystalline defects in free-flying nanoparticles. The present method analyzes single-particle diffraction patterns with more than one Bragg spot and extracts the angular correlations between pairs of Bragg spots in each image. The method was applied to the analysis of WAXS data of single xenon (Xe) nanoparticles recorded by single-shot X-ray diffraction using the Spring-8 Angstrom Compact free-electron LAser (SACLA) (Ishikawa et al., 2012) in Japan. The extracted angular correlations contain rich information on the crystalline structure of the nanoparticles, which cannot be accessed by conventional orientationally averaged diffraction data. The angular correlations were well reproduced by numerical simulation based on geometric calculations, following which we successfully characterized the stacking faults in the nanoparticles (Ferguson, 2016).

\section{Method}

\subsection{XFEL}

The experiments were performed at experimental hutch 2 of beamline 3 (Yabashi et al., 2017) of the SACLA. For details of the experimental setup, see also our previous publication (Nishiyama et al., 2019). The SACLA generated $1.1 \AA$ X-ray pulses at a repetition rate of $30 \mathrm{~Hz}$. The pulse duration was estimated to be $10 \mathrm{fs}$ [full width at half-maximum (FWHM)] (Inubushi et al., 2012). The XFEL pulses were focused on the reaction point by a set of $\mathrm{Be}$ compound reflection lenses (CRLs) (Katayama et al., 2019). The focused XFEL beam size was measured to be $\sim 1.5 \mu \mathrm{m}$ (FWHM). The X-ray fluence was evaluated to be $2 \times 10^{10}$ photons $\mu \mathrm{m}^{-2}$ by considering the transmittance of the beamline and the $\mathrm{Be}$ CRLs.

\subsection{Xe clusters}

Xe clusters were prepared by adiabatic expansion of Xe gas through a nozzle (Bostedt et al., 2012) with $200 \mu \mathrm{m}$ diameter 
Table 1

Statistics of the events.

The numbers of X-ray shots with hits are listed together with those used for the angular-correlation analysis. Note that the event rate is overestimated because of the low threshold in Bragg spots detection suitable for the angularcorrelation analysis.

\begin{tabular}{lll}
\hline & Number of X-ray shots & Event rate $(\%)$ \\
\hline Total X-ray shots & 573089 & \\
Images with hit(s) & 45843 & 8 \\
Images with $>1$ hit(s) & 3984 & 0.7 \\
$101_{\text {hcp }}-101_{\text {hcp }}$ & 802 & 0.1 \\
$111_{\text {fcc }}-111_{\text {fcc }}$ & 148 & 0.03 \\
$101_{\text {hcp }}-111_{\text {fcc }}$ & 456 & 0.08 \\
\hline
\end{tabular}

and $4^{\circ}$ half-opening angle. The nozzle temperature was $290 \mathrm{~K}$, the stagnation pressure was $3 \mathrm{MPa}$ and the average cluster size was estimated to be $\langle N\rangle \simeq 1.6 \times 10^{7}$ atoms (radius $\langle r\rangle \simeq 60 \mathrm{~nm}$ ) according to a known scaling law (Hagena, 1981). On average, the number of clusters contributing to each X-ray shot was less than one. In these experimental conditions, the sample intercepted an area $\sim 0.6 \%$ of that of the beam spot and therefore it can be assumed to be uniformly illuminated by coherent radiation with about $10^{8}$ photons.

\subsection{Collecting $X$-ray diffraction patterns}

The scattered X-rays from the Xe clusters were recorded on a shot-by-shot basis with a multi-port CCD sensor detector (Kameshima et al., 2014) located $100 \mathrm{~mm}$ downstream of the reaction point. We collected 573089 images in total. An averaged dark image was subtracted from the images. Images with Bragg spots were identified and selected using a blobfinding algorithm (Bradski, 2000). The statistics of the events are described in Table 1 . The number of images containing just one Bragg spot and more than one Bragg spot were $45843(\sim 8 \%)$ and $3984(\sim 0.7 \%)$, respectively.

\subsection{Angular correlation of two Bragg spots}

Fig. 1(a) depicts a schematic of the Ewald sphere (yellow) and the reciprocal lattice points (navy blue and red). Here we assume diffraction of a large-size perfect crystal. The reciprocal lattice points rotate about the origin of the reciprocal space depending on the crystal orientation. When a reciprocal lattice point lies on the surface of the Ewald sphere [red points in Figs. 1(a) and 1(b)] it gives rise to a Bragg spot on the detector. Furthermore, when another reciprocal lattice point also lies on the surface of the Ewald sphere another Bragg spot will be observed in the diffraction image. The probability of observing two Bragg peaks from a single crystal is lower than that of observing a single Bragg spot. When two Bragg spots from a single crystal do occur, their positions on the detector are correlated, as they are determined by the two corresponding momentum-transfer vectors [blue arrows in Fig. 1(b)].

Here, we describe the procedure of the angular-correlation analysis. First, we selected a certain arbitrary combination (with repetition allowed) of a pair of Debye-Scherrer rings in (a)

Detector

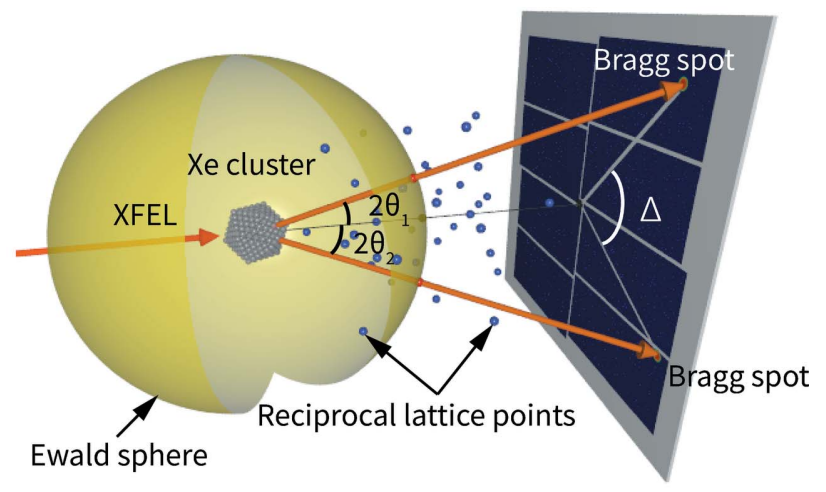

(b)

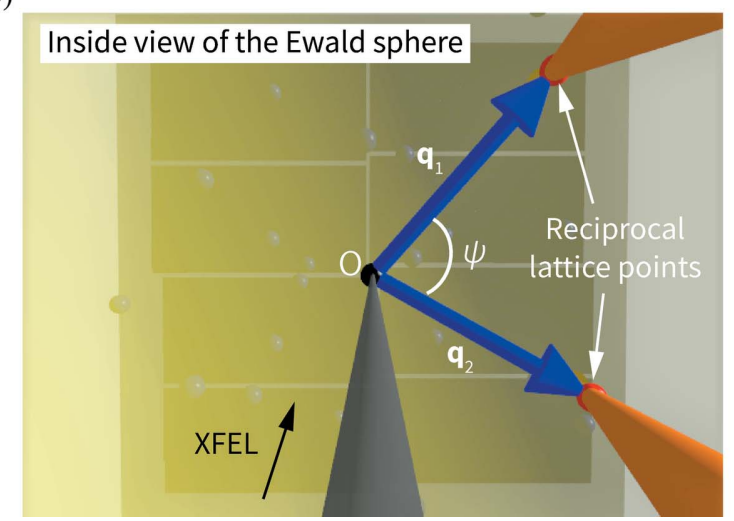

Figure 1

The geometry in reciprocal space together with the experimental configuration. (a) Ewald sphere (yellow) and reciprocal lattice points (navy blue and red) are depicted with the experimental configuration. $\theta_{1}$ and $\theta_{2}$ are Bragg angles and $\Delta$ is the azimuthal angular separation between the two Bragg spots. (b) Inside view of the Ewald sphere. $\psi$ is defined as the angle between the two corresponding momentum-transfer vectors: $\mathbf{q}_{1}$ and $\mathbf{q}_{2}$.

the powder diffraction pattern that can be formed by summing many single-shot diffraction images. We filtered diffraction images with Bragg spots located on the selected rings and used them for the angular-correlation analysis. In each diffraction image, the azimuthal angular separation $\Delta$ between two Bragg spots was calculated [see Fig. 1(a)]. We define $\psi$ as the angle between the two corresponding momentum-transfer vectors, $\mathbf{q}_{1}$ and $\mathbf{q}_{2}$, as follows,

$$
\cos \psi=\frac{\mathbf{q}_{1} \cdot \mathbf{q}_{2}}{\left|\mathbf{q}_{1}\right|\left|\mathbf{q}_{2}\right|} .
$$

$\operatorname{Cos} \psi$ is calculated using the following relation (Mendez et al., 2014, 2016),

$$
\cos \psi=\cos \theta_{1} \cos \theta_{2} \cos \Delta+\sin \theta_{1} \sin \theta_{2},
$$

where $\theta_{1}$ and $\theta_{2}$ are the Bragg angles at wavelength $\lambda$, as follows,

$$
\left|\mathbf{q}_{i}\right|=\frac{4 \pi \sin \theta_{i}}{\lambda}
$$

Note that $\psi$ approaches $\Delta$ in the small-angle limit $\theta_{1}, \theta_{2} \rightarrow 0$. The same procedure was iterated for pairs of Bragg spots in all 
diffraction images that were identified to contain Bragg spots and the correlation function $C(\cos \psi)$ was calculated as

$$
\begin{aligned}
C(\cos \psi)= & \sum_{j} \delta\left(\cos \psi-\cos \theta_{1}^{j} \cos \theta_{2}^{j} \cos \Delta^{j}\right. \\
& \left.-\sin \theta_{1}^{j} \sin \theta_{2}^{j}\right),
\end{aligned}
$$

where $j$ is an index for pairs of the Bragg spots and $\delta$ is the Dirac delta function. When an image contained more than two Bragg spots, $\cos \psi$ was evaluated for all combinations of the Bragg spots.

\section{Results and discussions}

\subsection{X-ray diffraction pattern}

Fig. 2(b) shows the distribution of the Bragg spot positions in the collected images as a function of the scattering angle $2 \theta$. This angle-integrated powder pattern displays three sharp peaks at positions corresponding to the $\{111\}_{\text {fcc }}$ (face-centered cubic) $+\{002\}_{\text {hcp }}$ (hexagonal close packed) reflections, the $\{200\}_{\text {fcc }}$ reflections and the $\{220\}_{\text {fcc }}+\{110\}_{\text {hcp }}$ reflections. In addition to those sharp peaks, a broad peak at $2 \theta \simeq 19.4^{\circ}$ is also observed. The position of this broad peak corresponds to the $\{101\}_{\mathrm{hcp}}$ reflection. It should be emphasized that the broad
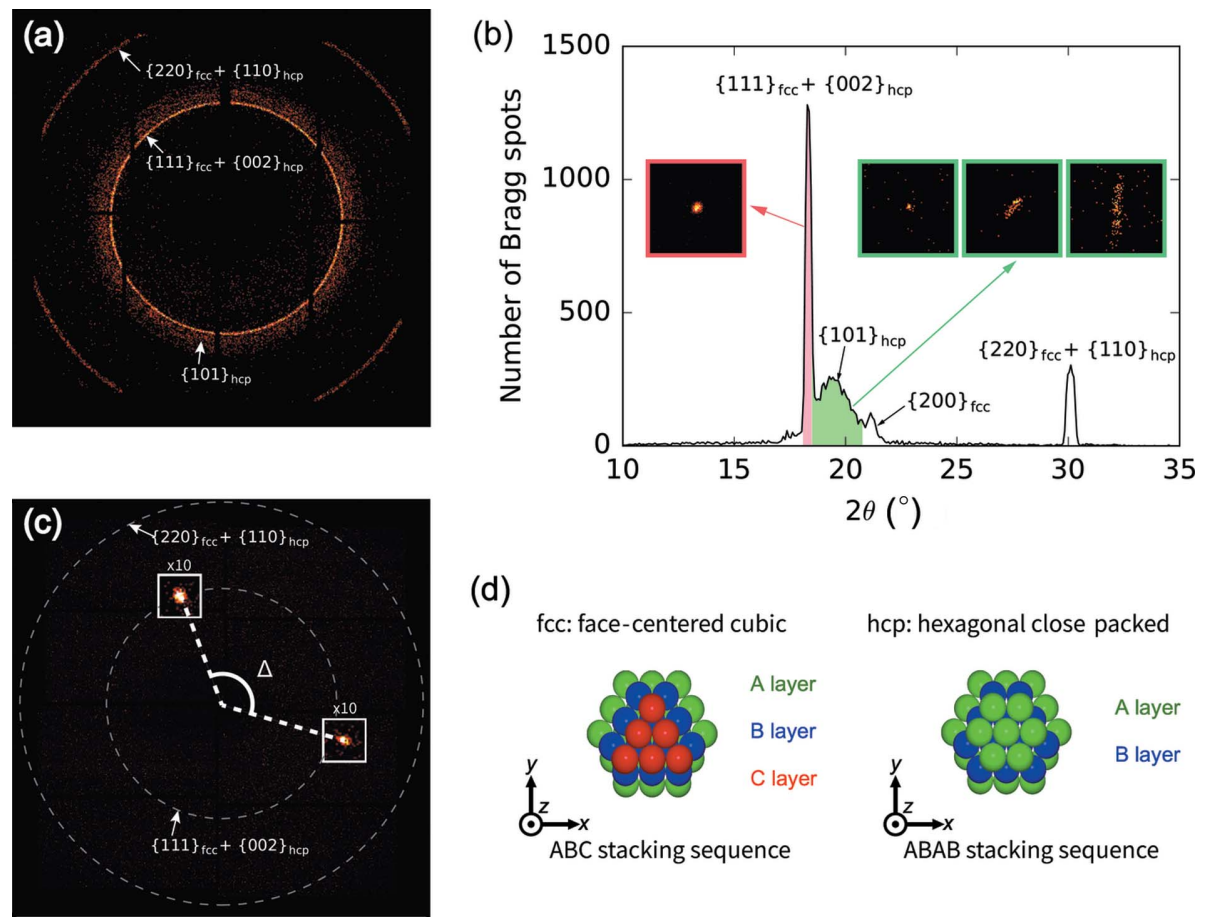

(d)

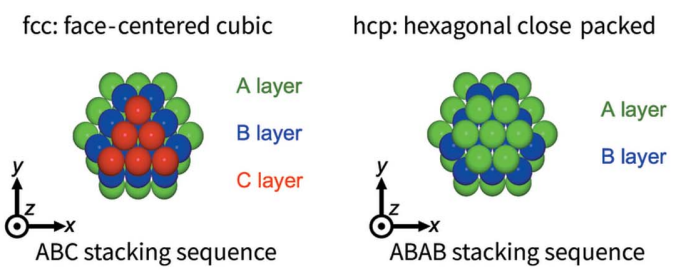

Figure 2

Distribution of the Bragg spot positions on the detector $(a)$ and as a function of $2 \theta(b)$. Three sharp peaks are observed at $2 \theta \simeq 18.3,21.1$ and $30.1^{\circ}$. These peak positions correspond to $\{111\}_{\mathrm{fcc}}+\{002\}_{\mathrm{hcp}}$, $\{200\}_{\text {fcc }}$ and $\{220\}_{\text {fcc }}+\{110\}_{\text {hcp }}$, respectively. In addition, one broad peak is observed at $2 \theta \simeq 19.4^{\circ}$, which corresponds to the $\{101\}_{\mathrm{hcp}}$ position. Note that the yield of the $\{220\}_{\mathrm{fcc}}+\{110\}_{\mathrm{hcp}}$ peak is undervalued because of the limit on the detection region. The angular correlations were calculated using spots lying on the $\{111\}_{\text {fcc }}+\{002\}_{\text {hcp }}$ peak $\left(18.1^{\circ}<2 \theta<18.5^{\circ}\right.$, filled with pink $)$ and the $\{101\}_{\text {hcp }}$ peak $\left(18.5^{\circ}<2 \theta<20.7^{\circ}\right.$, filled with green). Insets show the images of the Bragg spots located on the $\{111\}_{\text {fcc }}+\{002\}_{\text {hcp }}$ and $\{101\}_{\text {hcp }}$ peaks. (c) A representative single-shot image used for the angularcorrelation analysis. The image contains two Bragg spots on the $\{111\}_{\mathrm{fcc}}+\{002\}_{\mathrm{hcp}}$ and $\{101\}_{\mathrm{hcp}}$ rings. The areas marked by white rectangles are zoomed in $(\times 10)$. $(d)$ F.c.c. and h.c.p. stacking sequences. peak originates from bright spots distributed over a range of $2 \theta$ angles on the detector. This fact indicates that the broad peak originates from some long-range structural order in the Xe clusters. The coexistence of the f.c.c. and h.c.p. diffraction peaks has already been reported in previous diffraction experiments on rare-gas clusters (Waal et al., 2000; Danylchenko et al., 2004; Ferguson, 2016; Ferguson et al., 2016). These two structures only differ by the stacking sequence [ $A B C$ for f.c.c. and $A B A B$ for h.c.p., see Fig. $2(d)]$, and the free-energy difference is very small. Therefore, a mixture of structures along the stacking direction is commonly

The insets in Fig. 2(b) show some representative images of the Bragg spots located on each of the corresponding DebyeScherrer rings. Each Bragg spot typically consisted of $<200$ photons. Most of the Bragg spots located on the $\{111\}_{\mathrm{fcc}}+$ $\{002\}_{\text {hcp }}$ ring are circular shaped. On the other hand, elliptical and streaked spots are sometimes observed in the broad hop ring. These anisotropic intensities originate from not straightforward owing to the random orientations of the particles. In this article, we employ an angular-correlation analysis to extract meaningful information from the diffraction patterns of randomly oriented particles.

\subsection{Angular correlations of two Bragg spots}

By applying an angular-correlation analysis to shot-by-shot diffraction images, we can obtain further structural details beyond what is possible with a 1D powder diffraction pattern. A representative image used for the angular-correlation analysis is shown in Fig. 2(c). Our angular-correlation analysis was applied in the cases of Bragg spots lying on the rings corresponding to the $\{111\}_{\text {fcc }}+\{002\}_{\text {hcp }}$ reflections $\left(18.1^{\circ}<2 \theta<18.5^{\circ}\right)$ and the $\{101\}_{\text {hcp }}$ reflections $\left(18.5^{\circ}<2 \theta<20.7^{\circ}\right)$ [see Fig. 2(a)]. For convenience, we refer to these rings (and their corresponding peaks in the $1 \mathrm{D}$ plot) as $\{111\}_{\mathrm{fcc}}$ and $\{101\}_{\mathrm{hcp}}$, respectively. Note that the $\{220\}_{\text {fcc }}+\{110\}_{\text {hcp }}$ ring was not used for the angular-correlation analysis because we could not record the whole ring owing to the limited detection area. Angular correlations were calculated for three combinations of pairs of rings: $\{101\}_{\mathrm{hcp}}-\{101\}_{\mathrm{hcp}}$, $\{111\}_{\mathrm{fcc}}-\{111\}_{\mathrm{fcc}}$ and $\{101\}_{\mathrm{hcp}}-$ $\{111\}_{\text {fcc }}$. We adopted a lower threshold 

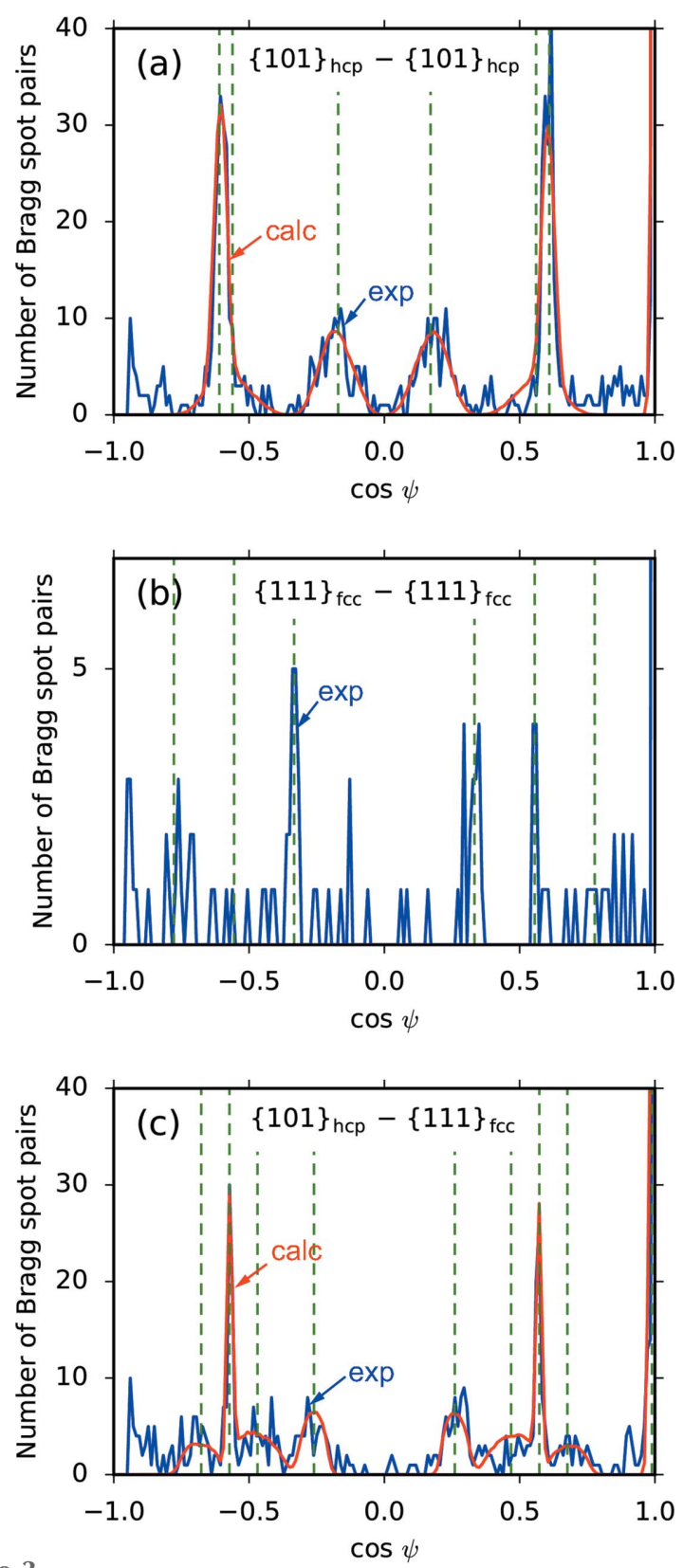

Figure 3

Results of angular-correlation analysis. The number of Bragg spot pairs are shown as functions of $\cos \psi$. Blue lines depict the experimental angular correlations of $(a)\{101\}_{\mathrm{hcp}}-\{101\}_{\mathrm{hcp}},(b)\{111\}_{\mathrm{fcc}}-\{111\}_{\mathrm{fcc}}$ and (c) $\{101\}_{\mathrm{hcp}}-\{111\}_{\mathrm{fcc}}$. Green dashed lines depict the peak positions of the angular correlations calculated by evaluating $\cos \psi$ for the two corresponding reciprocal lattice vectors (see Appendix $A$ ). Numerical simulations were performed to account for the peak broadening in $(a)$ and (c) (red lines). The details of the simulation are provided in the main text. The optimized parameters in the simulation are $\sigma_{x y}=0.02 \AA^{-1}$ and $\sigma_{z}=0.25 \AA^{-1}$.

for the blob-finding algorithm than that used in the calculation of the 1D powder diffraction pattern because the angularcorrelation analysis is less susceptible to false spots owing to noise in the images. In addition, we excluded eight images containing more than five Bragg spots in any of the selected rings, which otherwise result in uncorrelated noise in the angular correlations.
The angular correlation of $\{101\}_{\mathrm{hcp}}-\{101\}_{\mathrm{hcp}}$ is indicated by the blue line in Fig. 3(a). Note that the correlation around $\cos \psi \simeq-1$ is not available because of the geometrical limit of $\psi$ (Mendez et al., 2016). The peak positions in the angular correlation agree with the prediction [green dashed lines in Fig. 3(a)] made by evaluating $\cos \psi$ for two $\{101\}_{\text {hcp }}$ reciprocal lattice vectors (see Appendix A1). In addition, the peaks in the angular correlation are broad. If one assumes perfect crystals with infinite volume, the structure factor has sharp peaks at the reciprocal lattice points; consequently, the angular correlation would also have sharp peaks. Therefore, the peak widths in Fig. 3(a) indicate a structure factor with a diffuse intensity distribution around the reciprocal lattice points.

Fig. 3(b) shows the angular correlation for $\{111\}_{\mathrm{fcc}}-$ $\{111\}_{\text {fcc }}$. In contrast to the frequent occurrence of pairs of $\{101\}_{\text {hcp }}$ Bragg spots, the number of pairs of $\{111\}_{\text {fcc }}$ Bragg spots is much less. This is surprising if one considers the huge number of recorded $\{111\}_{\mathrm{fcc}}$ spots [see Fig. $2(b)$ ]. One might consider that this is because of the geometrical tolerance of the Bragg conditions. If the structure factor has sharp peaks around the reciprocal lattice points, the crystals must be oriented very accurately in order to give rise to two correlated Bragg spots. We will return to this point later in Section 3.4. The correlation has small but significant peaks at $\cos \psi=-1 / 3$, $1 / 3$ and $5 / 9$. The significance of these peaks was $5.8 \sigma, 4.7 \sigma$ and $4.3 \sigma$, respectively, which were calculated by assuming a noise level of 0.5 pairs bin ${ }^{-1}$. These peak positions agree with the prediction considering reciprocal lattice points for f.c.c. crystals with twinned faults (Mendez et al., 2016) (see also Appendix A2). Furthermore, the number of uncorrelated Bragg spot pairs should also be noticed. Uncorrelated Bragg spot pairs can originate from polycrystalline structures with randomly oriented crystalline domains or multiple clusters in the XFEL focus. In the present case, the number of uncorrelated Bragg spot pairs is reasonably explained by the presence of multiple clusters in the XFEL focus. This fact implies that most of the Xe clusters do not form polycrystalline structures.

The $\{101\}_{\text {hcp }}$ and $\{111\}_{\text {fcc }}$ Bragg spots show clear angular correlation [see Fig. 3(c)]. The clear correlation indicates that pairs of $\{101\}_{\mathrm{hcp}}$ and $\{111\}_{\mathrm{fcc}}$ Bragg spots originated from single particles and not from independent particles with different crystalline structures. The vertical green dashed lines in Fig. 3(c) indicate the peak positions predicted by considering the f.c.c.-h.c.p. mixture structure along the stacking direction (see Appendix A3). The peak positions are successfully explained by the prediction. Furthermore, peaks in the angular correlation exhibit specific peak widths. As will be seen later, the non-uniform widths of the angular-correlation peaks result from an anisotropic diffuse intensity around the reciprocal lattice points.

\subsection{Numerical simulation of angular correlations}

We developed a numerical simulation method to model and fit the intensity distribution around the reciprocal lattice points. In the simulation, we considered 3D peak broadening 
around the $\{101\}_{\text {hcp }}$ reciprocal lattice points, which are expressed as a sum of Gaussian functions,

$$
\begin{aligned}
I_{\{101\}}^{\mathrm{hcp}}(\mathbf{q}) \propto & \sum_{\mathbf{G} \in g_{\{101\}}^{\mathrm{hcp}}} \exp \left[-\frac{\left(q_{x}-G_{x}\right)^{2}+\left(q_{y}-G_{y}\right)^{2}}{2 \sigma_{x y}^{2}}\right. \\
& \left.-\frac{\left(q_{z}-G_{z}\right)^{2}}{2 \sigma_{z}^{2}}\right],
\end{aligned}
$$

with the $z$ axis along the $[111]_{\mathrm{fcc}}$ direction. $g_{\{101\}}^{\text {hcp }}$ is the set of $\{101\}_{\text {hep }}$ reciprocal lattice vectors. The angular correlation was modeled with the following function,

$$
\begin{aligned}
C(\cos \psi) \propto & \int_{V_{\{101\}}^{\text {hcp }}} \mathrm{d} \mathbf{q}_{1} \int_{V_{\{101\}}^{\text {hcp }}} \mathrm{d} \mathbf{q}_{2} I_{\{101\}}^{\mathrm{hcp}}\left(\mathbf{q}_{1}\right) I_{\{101\}}^{\mathrm{hcp}}\left(\mathbf{q}_{2}\right) P\left(\mathbf{q}_{1}, \mathbf{q}_{2}\right) \\
& \times \delta\left(\cos \psi-\frac{\mathbf{q}_{1} \cdot \mathbf{q}_{2}}{\left|\mathbf{q}_{1}\right|\left|\mathbf{q}_{2}\right|}\right)
\end{aligned}
$$

and

$$
P\left(\mathbf{q}_{1}, \mathbf{q}_{2}\right)=\frac{2 \delta_{1} \delta_{2}}{\pi\left|\mathbf{q}_{1}\right|\left|\mathbf{q}_{2}\right| \cos \theta_{1} \cos \theta_{2} \sin \Delta},
$$

where $P\left(\mathbf{q}_{1}, \mathbf{q}_{2}\right)$ is the probability that two small spheres around $\mathbf{q}_{1}$ and $\mathbf{q}_{2}$ with radii of $\delta_{1}$ and $\delta_{2}$, respectively, intersect with the Ewald sphere simultaneously. The integral in equation (6) was taken over the region $V_{\{101\}}^{\text {hcp }}$, which specifies the momentum-transfer region of $\{101\}_{\text {hcp }}$ used to construct the angular correlation. We used the Monte Carlo method to calculate the integral, in which reciprocal lattice vectors were perturbed randomly with a Gaussian distribution, as represented in equation (5). The width parameters, $\sigma_{x y}$ and $\sigma_{z}$, as well as the constant of proportionality in equation (6) were optimized to reproduce the experimental angular correlation in Fig. 3(a).

\subsection{Stacking faults in the Xe clusters}

The red line in Fig. 3(a) depicts the simulation results with the optimized parameters: $\sigma_{x y}=0.02 \AA^{-1}$ and $\sigma_{z}=0.25 \AA^{-1}$. The simulation results successfully reproduced the experimental angular correlation, including the characteristic widths of the peaks. The optimized parameters suggest that the structure factor has a rodlike intensity distribution around the $\{101\}_{\text {hcp }}$ reciprocal lattice points which extends in the $[111]_{\mathrm{fcc}}$ direction, parallel to the $[001]_{\mathrm{hcp}}$ direction [see Fig. 4(a)]. The rod-like intensity distributions are called Bragg scattering rods. We also performed a similar simulation for the $\{101\}_{\text {hcp }}-\{111\}_{\text {fcc }}$ correlation [red line in Fig. 3(c)] and we successfully explained the experimental result by assuming the same intensity distributions around the $\{101\}_{\text {hcp }}$ reciprocal lattice points described with the same parameters $\sigma_{x y}$ and $\sigma_{z}$, as in the previous case (see Appendix $B$ for details).

Our findings from the angular-correlation analysis are supported by the profiles of the Bragg spots in the single-shot diffraction patterns. In fact, the elliptical and streaked spots observed in the $\{101\}_{\text {hcp }}$ peak region are parts of the Bragg scattering rods resulting from the stacking faults. The profiles of the Bragg spots vary depending on the orientation of the crystal and hence on the orientation of the reciprocal lattice in reciprocal space, i.e. how the Bragg scattering rods intersect the Ewald sphere. Streaked patterns are observed when one of the Bragg scattering rods is nearly in contact with and tangential to the Ewald sphere. The single-shot diffraction patterns encode structural information on single particles and it is possible to discuss the particle-by-particle structural information using the single-shot diffraction patterns. However, it is challenging to retrieve the structural information from the single-shot diffraction data and such analysis is beyond the scope of this study.

To understand the origin of the diffuse scattering intensity, we employ the diffraction theory of close-packed crystals containing stacking faults (Paterson, 1952). According to the theory, when a crystal contains stacking faults, two types of peak broadening occur in reciprocal space. Here, we use the notation $(h k l)_{\text {hcp }}$ to represent the reflections. For reflections that satisfy the condition $h-k=3 n$ ( $n=$ an integer), the peak widths are not affected by the stacking order and the widths reflect the size of the entire close-packed crystal (through an inverse relationship). On the other hand, if $h-k=3 n \pm 1$, the widths depend on the stacking order. The structure factor has a broad intensity distribution along the $[001]_{\text {hcp }}$ direction, which results in the emergence of Bragg scattering rods. Theoretically, the degree of stacking faults is described with a parameter $\alpha$, which is the probability that the $N$ th and $(N+$ 2)th layers have different stacking positions $A B C$. $\alpha=1$ corresponds to f.c.c., $\alpha=0$ to h.c.p. and $\alpha=0.5$ to random hexagonal close packed (r.h.c.p.) structure. (a)

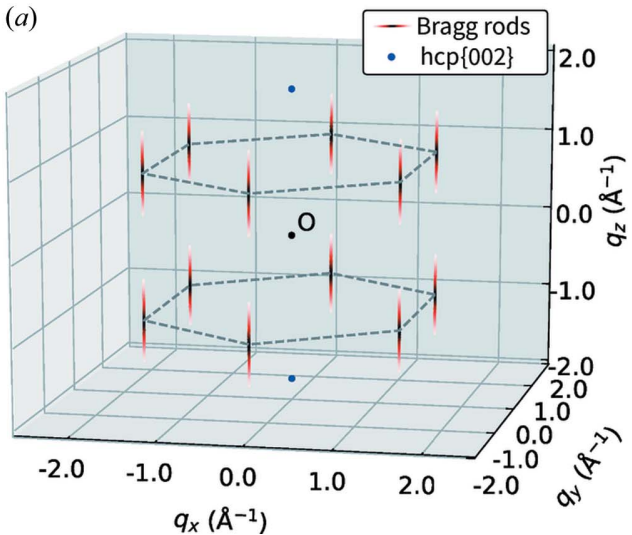

Figure 4

(a) Structure factor when $\alpha=0.5$. The structure factor has 12 Bragg scattering rods (red rods) around the $\{101\}_{\text {hcp }}$ reciprocal lattice points and two sharp peaks (blue points) at the $\{002\}_{\text {hcp }}$ reciprocal lattice points. The integral breadth $\beta$ of the Bragg scattering rods is theoretically calculated to be $0.59 \AA^{-1}$. (b) An example of the r.h.c.p. structure in the Xe clusters.

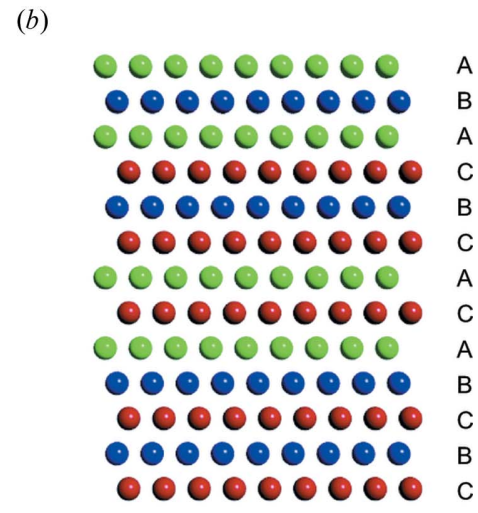


The experimental results agree well with the r.h.c.p. structure: $\alpha=0.5$. Fig. 4(a) shows the schematics of the 3D structure factor when $\alpha=0.5$. The figure depicts only the intensities that are related to the discussion of the angular correlations. The structure factor has two sharp peaks at $\{002\}_{\mathrm{hcp}}$ [i.e. (111) $)_{\mathrm{fcc}}$ and $(\overline{111})_{\text {fcc }}$ ] reciprocal lattice points [blue points in Fig. 4(a)]. In addition, there are 12 Bragg scattering rods that have broad intensity distributions around the $\{101\}_{\text {hcp }}$ reciprocal lattice points [red rods in Fig. 4(a)]. Here, we verify the consistency between the experimental results and the structure factor when $\alpha=0.5$. First, the structure factor is in agreement with the $1 \mathrm{D}$ diffraction pattern. The sharp ring at $2 \theta \simeq 18.3^{\circ}$ originates from the sharp intensity at $\{002\}_{\text {hcp }}$ and the broad ring at $2 \theta \simeq 19.4^{\circ}$ originates from the Bragg scattering rods. The slight $\{200\}_{\text {fcc }}$ ring at $2 \theta \simeq 21.1^{\circ}$ cannot be explained by the structure factor and the observation of this ring suggests the existence of a small amount of nearly perfect f.c.c. crystals. However, it has little influence on the following discussion on the angular correlations. Secondly, peak positions in the angular correlations agree with the structure factor. As mentioned above, the peak positions are successfully explained by considering $\{101\}_{\text {hcp }}$ and $\{111\}_{\text {fcc }}$ reciprocal lattice points, and the structure factor has finite intensity around the reciprocal lattice points. Thirdly, the diffuse intensities around the $\{101\}_{\text {hcp }}$ reciprocal lattice points are also consistent with the random stacking case. According to the theory (Paterson, 1952), the integral breadth of the Bragg scattering rods, which is defined as the ratio of the integrated intensity along a rod to the maximum intensity, is expressed as follows,

$$
\beta_{\mathrm{th}}=\frac{2 \pi}{d} \frac{1-[1-3 \alpha(1-\alpha)]^{1 / 2}}{1+[1-3 \alpha(1-\alpha)]^{1 / 2}},
$$

where $d=a^{\mathrm{fcc}}(3)^{-1 / 2}$ is the spacing between two close-packed layers and $a^{\text {fcc }}=6.14 \AA$ is the lattice constant of the f.c.c. crystal. Substituting $\alpha=0.5$ into equation (8), the integral breadth of the Bragg scattering rods is calculated to be $\beta_{\text {th }}=$ $0.59 \AA^{-1}$. This value is in reasonable agreement with the value estimated from the angular correlations $\beta_{\exp }=(2 \pi)^{1 / 2} \sigma_{z}=$ $0.63 \AA^{-1}$. It is noteworthy that the peak broadening caused by the finite crystal size is almost negligible compared with that caused by the stacking faults. Finally, we can explain the small amount of correlated Bragg spot pairs in the $\{111\}_{\mathrm{fcc}}-\{111\}_{\mathrm{fcc}}$ correlation. Most of the $\{111\}_{\text {fcc }}$ Bragg spots originate from the sharp peaks at $\{002\}_{\mathrm{hcp}}$ and no correlated Bragg spot pairs are detectable from these two peaks. The slight correlation is because of the contamination from the Bragg scattering rods; we cannot distinguish the $\{002\}_{\text {hcp }}$ Bragg spots from those originating from the Bragg scattering rods.

The present method provides new insight into the structure of nanoparticles. The angular-correlation analysis revealed that in the present case of large Xe clusters they do not form a multi-domain structure but form single close-packed crystals with random stacking orders. Previous studies suggested that small rare-gas clusters form multiply twinned structures with fivefold symmetry (Farges et al., 1983). However, in the present study, we found no evidence of fivefold twinning. This might imply a structural transition in the growth process from the fivefold twinned structure to the non-twinned structure. The possibility of an r.h.c.p. structure in rare-gas clusters has already been suggested in a previous study on Ar clusters (with $\langle N\rangle \simeq 80000$ atoms) (Waal et al., 2000). The present study suggests that even much larger clusters $\left(\langle N\rangle \simeq 10^{7}\right.$ atoms) can form an r.h.c.p. structure. The formation of an r.h.c.p. structure appears to be related to the growth kinetics of the rare-gas clusters.

\section{Summary and outlook}

In summary, we explored the structural properties of Xe clusters by means of single-shot WAXS data from free-flying single nanoparticles as recorded at an XFEL. Our data revealed evident angular correlations between the Bragg spots in the single-shot diffraction patterns. We compared the observed angular correlations with the results of a newly developed simulation code, which combines the theory of diffuse X-ray scattering with geometrical considerations. From the comparison, we found evidence for an r.h.c.p. structure in the Xe nanoparticles. The results of this study on Xe nanoparticles validate our novel approach for structural analysis and characterization of defects in individual 3D nanoparticles based on single-shot X-ray diffraction data of free-flying atomic clusters and simulations.

\section{APPENDIX $A$}

Peak positions in angular correlations

\section{A1. $\{101\}_{\text {hcp }}-\{101\}_{\text {hcp }}$}

The peak positions in the angular correlation are calculated as follows. First, we define the primitive reciprocal lattice vectors for h.c.p.,

$$
\left\{\begin{array}{l}
\mathbf{b}_{1}^{\text {hcp }}=\frac{2 \pi}{a^{\text {hcp }}}\left(1, \frac{1}{3^{1 / 2}}, 0\right) \\
\mathbf{b}_{2}^{\text {hcp }}=\frac{2 \pi}{a^{\text {hcp }}}\left(0, \frac{2^{1 / 2}}{3}, 0\right), \\
\mathbf{b}_{3}^{\text {hcp }}=\frac{2 \pi}{c^{\text {hcp }}}(0,0,1)
\end{array},\right.
$$

where $a^{\text {hcp }}$ and $c^{\text {hcp }}=(8 / 3)^{1 / 2} a^{\text {hcp }}$ are lattice constants of the h.c.p. crystal. Reciprocal lattice vectors $\mathbf{G}_{h k l}^{\mathrm{hcp}}$ are expressed by the linear combinations of the primitive reciprocal lattice vectors,

$$
\mathbf{G}_{h k l}^{\mathrm{hcp}}=h \mathbf{b}_{1}^{\mathrm{hcp}}+k \mathbf{b}_{2}^{\mathrm{hcp}}+l \mathbf{b}_{3}^{\mathrm{hcp}},
$$

where $h, k$ and $l$ are integers. The $\{101\}_{\text {hcp }}$ reflection has 12 equivalent reciprocal lattice vectors:

$$
\begin{aligned}
& g_{\{101\}}^{\text {hcp }}=\left\{\mathbf{G}_{101}^{\text {hcp }}, \mathbf{G}_{1 \overline{1} 1}^{\text {hcp }}, \mathbf{G}_{011}^{\text {hcp }}, \mathbf{G}_{0 \overline{1}}^{\text {hcp }}, \mathbf{G}_{\overline{1} 11}^{\text {hcp }}, \mathbf{G}_{\overline{1} 01}^{\text {hcp }},\right. \\
& \left.\mathbf{G}_{10 \overline{1}}^{\text {hcp }}, \mathbf{G}_{1 \overline{1} 1}^{\text {hcp }}, \mathbf{G}_{01 \overline{1}}^{\text {hcp }}, \mathbf{G}_{0 \overline{1} 1}^{\text {hcp }}, \mathbf{G}_{\overline{1} 1 \overline{1}}^{\text {hcp }}, \mathbf{G}_{\overline{1} 0 \overline{1}}^{\text {hcp }}\right\} .
\end{aligned}
$$

The peak positions are obtained by calculating $\cos \psi$ for all combinations of two vectors from $g_{\{101\}}^{\text {hcp }}$, 


$$
\begin{aligned}
& \left\{\cos \psi=\frac{\mathbf{G}_{1} \cdot \mathbf{G}_{2}}{\left|\mathbf{G}_{1}\right|\left|\mathbf{G}_{2}\right|} \mid \mathbf{G}_{1}, \mathbf{G}_{2} \in g_{\{101\}}^{\text {hcp }}\right\} \\
& =\left\{ \pm \frac{7}{41}, \pm \frac{23}{41}, \pm \frac{25}{41}, \pm 1\right\} \simeq\{ \pm 0.17, \pm 0.56, \pm 0.61, \pm 1.00\}
\end{aligned}
$$

\section{A2. $\{111\}_{\mathrm{fcc}}-\{111\}_{\mathrm{fcc}}$}

The peak positions in the $\{111\}_{\mathrm{fcc}}-\{111\}_{\mathrm{fcc}}$ correlation are calculated in a similar manner to the $\{101\}_{\mathrm{hcp}}-\{101\}_{\mathrm{hcp}}$ correlation. The primitive reciprocal lattice vectors of f.c.c. and the reciprocal lattice vectors are

$$
\left\{\begin{array}{l}
\mathbf{b}_{1}^{\mathrm{fcc}}=\frac{2 \pi}{a^{\mathrm{fcc}}}(1,0,0) \\
\mathbf{b}_{2}^{\mathrm{fcc}}=\frac{2 \pi}{a^{\mathrm{fcc}}}(0,1,0) \\
\mathbf{b}_{3}^{\mathrm{fcc}}=\frac{2 \pi}{a^{\mathrm{fcc}}}(0,0,1)
\end{array}\right.
$$

and

$$
\mathbf{G}_{h k l}^{\mathrm{fcc}}=h \mathbf{b}_{1}^{\mathrm{fcc}}+k \mathbf{b}_{2}^{\mathrm{fcc}}+l \mathbf{b}_{3}^{\mathrm{fcc}},
$$

The set of $\{111\}_{\mathrm{fcc}}$ reciprocal lattice vectors is defined as $g_{\{111\}}^{\mathrm{fcc}}$.

$$
g_{\{111\}}^{\mathrm{fcc}}=\left\{\mathbf{G}_{111}^{\mathrm{fcc}}, \mathbf{G}_{11 \overline{1}}^{\mathrm{fcc}}, \mathbf{G}_{\overline{1} 1 \overline{1}}^{\mathrm{fcc}}, \mathbf{G}_{1 \overline{1} 1}^{\mathrm{fcc}}, \mathbf{G}_{\overline{111}}^{\mathrm{fcc}}, \mathbf{G}_{\overline{11} 1}^{\mathrm{fcc}}, \mathbf{G}_{1 \overline{1} 1}^{\mathrm{fcc}}, \mathbf{G}_{\overline{1} 11}^{\mathrm{fcc}}\right\}
$$

When the f.c.c. crystal contains a twinned fault (i.e. expressed by a stacking sequence: ...ABCABCBACBA ...), we should consider an extended set of momentum-transfer vectors, which is expressed with a reflection operator $\mathbf{T}$ across the (111) fcc plane (Mendez et al., 2016):

$$
g_{\{111\}}^{\mathrm{fcctwin}}=g_{\{111\}}^{\mathrm{fcc}} \cup\left\{\mathbf{T} \cdot \mathbf{G} \mid \mathbf{G} \in g_{\{111\}}^{\mathrm{fcc}}\right\}
$$

and

$$
\mathbf{T}=\left(\begin{array}{ccc}
\frac{1}{3} & -\frac{2}{3} & -\frac{2}{3} \\
-\frac{2}{3} & \frac{1}{3} & -\frac{2}{3} \\
-\frac{2}{3} & -\frac{2}{3} & \frac{1}{3}
\end{array}\right) .
$$

The peak positions are obtained by calculating $\cos \psi$ for all combinations of two vectors from $g_{\{111\}}^{\text {fcctwin }}$.

$$
\begin{aligned}
& \left\{\cos \psi=\frac{\mathbf{G}_{1} \cdot \mathbf{G}_{2}}{\left|\mathbf{G}_{1}\right|\left|\mathbf{G}_{2}\right|} \mid \mathbf{G}_{1}, \mathbf{G}_{2} \in g_{\{111\}}^{\text {fcctwin }}\right\} \\
& =\left\{ \pm \frac{1}{3}, \pm \frac{5}{9}, \pm \frac{7}{9}, \pm 1\right\} \simeq\{ \pm 0.33, \pm 0.56, \pm 0.78, \pm 1.00\}
\end{aligned}
$$

\section{A3. $\{101\}_{\mathrm{hcp}}-\{111\}_{\mathrm{fcc}}$}

In order to predict the peak positions in the $\{101\}_{\mathrm{hcp}}-$ $\{111\}_{\mathrm{fcc}}$ correlation, we need to consider both $\{101\}_{\mathrm{hcp}}$ and $\{111\}_{\text {fcc }}$ reciprocal lattice points. We assume a mixture of the f.c.c. and h.c.p. structures along the stacking direction, which is, for example, expressed by a stacking sequence: $\ldots A B C A B C A B A B \ldots$ The reciprocal lattice vectors for f.c.c., $\mathbf{G}_{h k l}^{\mathrm{fcc}}$, are expressed as follows:

$$
\mathbf{G}_{h k l}^{\mathrm{fcc}}=\mathbf{R}\left(h \mathbf{b}_{1}^{\mathrm{fcc}}+k \mathbf{b}_{2}^{\mathrm{fcc}}+l \mathbf{b}_{3}^{\mathrm{fcc}}\right),
$$

and

$$
\mathbf{R}=\left(\begin{array}{ccc}
\frac{1}{2^{1 / 2}} & -\frac{1}{2^{1 / 2}} & 0 \\
-\frac{1}{6^{1 / 2}} & -\frac{1}{6^{1 / 2}} & \frac{2}{6^{1 / 2}} \\
\frac{1}{3^{1 / 2}} & \frac{1}{3^{1 / 2}} & \frac{1}{3^{1 / 2}}
\end{array}\right) .
$$

$\mathbf{R}$ is a rotation matrix for converting the coordinates to those common to h.c.p. The peak positions are obtained by calculating $\cos \psi$ for all combinations of two vectors from $g_{\{101\}}^{\text {hpp }}$ and $g_{\{111\}}^{\mathrm{fcc}}$.

$$
\begin{aligned}
& \left\{\cos \psi=\frac{\mathbf{G}_{1} \cdot \mathbf{G}_{2}}{\left|\mathbf{G}_{1}\right|\left|\mathbf{G}_{2}\right|} \mid \mathbf{G}_{1} \in g_{\{101\}}^{\mathrm{hcp}}, \mathbf{G}_{2} \in g_{\{111\}}^{\mathrm{fcc}}\right\} \\
& =\left\{ \pm \frac{5}{3(41)^{1 / 2}}, \pm \frac{3}{41^{1 / 2}}, \pm \frac{11}{3(41)^{1 / 2}}, \pm \frac{13}{3(41)^{1 / 2}}, \pm \frac{19}{3(41)^{1 / 2}}\right\} \\
& \simeq\{ \pm 0.26, \pm 0.47, \pm 0.57, \pm 0.68, \pm 0.99\} .
\end{aligned}
$$

Note that the peak positions remain the same even when the f.c.c. crystal contains a twin fault.

\section{APPENDIX $B$}

\section{Simulation of angular correlation}

B1. $\{101\}_{\text {hcp }}-\{111\}_{\text {fcc }}$

The scattering intensity $I_{\{111\}}^{\mathrm{fcc}}$ around the $\{111\}_{\mathrm{fcc}}$ reciprocal lattice points is formulated as follows. We neglect the peak broadening around the $\{111\}_{\mathrm{fcc}}$ reciprocal lattice points. This is verified by the fact that the peak broadening in the angular correlations is dominated by the diffuse intensity distribution of the Bragg rods. When a crystal contains stacking faults, elements of the set $g_{\{111\}}^{\text {fctwin }}$ are no longer equivalent. Therefore, we should consider the scattering intensity

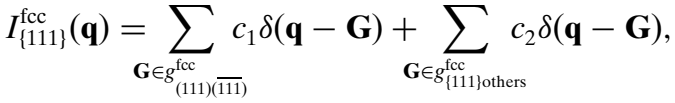

$$
\begin{aligned}
& g_{(111)(\overline{111})}^{\mathrm{fcc}}=\left\{\mathbf{G}_{111}^{\mathrm{fcc}}, \mathbf{G}_{\overline{111}}^{\mathrm{fcc}},\right\}
\end{aligned}
$$

and

$$
g_{\{111\} \text { others }}^{\mathrm{fcc}}=g_{\{111\}}^{\mathrm{fcctwin}} \backslash g_{(111)(\overline{111})}^{\mathrm{fcc}},
$$

where $c_{1}$ and $c_{2}$ are constants. In the present case, we used $c_{1}=1$ and $c_{2}=0.5$ to reproduce the experimental result.

Using the expressions for $I_{\{101\}}^{\mathrm{hcp}}$ and $I_{\{111\}}^{\mathrm{fcc}}$, the angular correlation for $\{101\}_{\mathrm{hcp}}-\{111\}_{\mathrm{fcc}}$ was modeled with the following function,

$$
\begin{aligned}
C(\cos \psi) \propto & \int_{\substack{\mathrm{h} \text { cp } \\
\operatorname{l1011}}} \mathrm{d} \mathbf{q}_{1} \int \mathrm{d} \mathbf{q}_{2} I_{\{101\}}^{\mathrm{hcp}}\left(\mathbf{q}_{1}\right) I_{\{111\}}^{\mathrm{fcc}}\left(\mathbf{q}_{2}\right) P\left(\mathbf{q}_{1}, \mathbf{q}_{2}\right) \\
& \times \delta\left(\cos \psi-\frac{\mathbf{q}_{1} \cdot \mathbf{q}_{2}}{\left|\mathbf{q}_{1}\right|\left|\mathbf{q}_{2}\right|}\right) .
\end{aligned}
$$




\section{Acknowledgements}

We are grateful to the late Makoto Yao for his invaluable contributions to the present work. The experiments were performed at SACLA with the approval of JASRI and the program review committee (Nos. 2016A8057 and 2016B8077).

\section{Funding information}

This study was supported by the X-ray Free-Electron Laser Utilization Research Project and the X-ray Free-Electron Laser Priority Strategy Program of the Ministry of Education, Culture, Sports, Science and Technology of Japan (MEXT), by the Proposal Program of SACLA Experimental Instruments of RIKEN, by the Japan Society for the Promotion of Science (JSPS) KAKENHI Grant Nos. JP15K17487 and JP16K05016, by JSPS Grant-in-Aid for JSPS Fellows No. JP19J14969, by JSPS and Consiglio Nazionale delle Ricerche (CNR) under the Japan-Italy Research Cooperative Program, and by the IMRAM project. YK, MB and CB acknowledge support from the US Department of Energy, Office of Science, Basic Energy Sciences, Chemical Sciences, Geosciences and Biosciences Division. AN and TN acknowledge support from the Research Program for Next Generation Young Scientists of 'Dynamic Alliance for Open Innovation Bridging Human, Environment and Materials' in 'Network Joint Research Center for Materials and Devices'. HF and KU acknowledge support from the Dynamic Alliance for Open Innovation Bridging Human, Environment and Materials. DY acknowledges support from the Grant-In-Aid of Tohoku University Institute for Promoting Graduate Degree Programs Division for Interdisciplinary Advanced Research and Education. GR, DEG, TP and AC acknowledge support from NOXSS PRIN contract of Ministero dell'Istruzione, dell'Università e della Ricerca (MIUR), Italy. KN acknowledges support from the Research Program of 'Dynamic Alliance for Open Innovation Bridging Human, Environment and Materials' in 'Network Joint Research Center for Materials and Devices'.

\section{References}

Alivisatos, A. P. (1996). Science, 271, 933-937.

Aquila, A., Barty, A., Bostedt, C., Boutet, S., Carini, G., dePonte, D., Drell, P., Doniach, S., Downing, K. H., Earnest, T., Elmlund, H., Elser, V., Gühr, M., Hajdu, J., Hastings, J., Hau-Riege, S. P., Huang, Z., Lattman, E. E., Maia, F. R. N. C., Marchesini, S., Ourmazd, A., Pellegrini, C., Santra, R., Schlichting, I., Schroer, C., Spence, J. C. H., Vartanyants, I. A., Wakatsuki, S., Weis, W. I. \& Williams, G. J. (2015). Struct. Dyn. 2, 041701.

Barke, I., Hartmann, H., Rupp, D., Flückiger, L., Sauppe, M., Adolph, M., Schorb, S., Bostedt, C., Treusch, R., Peltz, C., Bartling, S., Fennel, T., Meiwes-Broer, K.-H. \& Möller, T. (2015). Nat. Commun. 6, 6187.

Bawendi, M. G., Steigerwald, M. L. \& Brus, L. E. (1990). Annu. Rev. Phys. Chem. 41, 477-496.

Bostedt, C., Adolph, M., Eremina, E., Hoener, M., Rupp, D., Schorb, S., Thomas, H., de Castro, A. R. B. \& Möller, T. (2010). J. Phys. B At. Mol. Opt. Phys. 43, 194011.

Bostedt, C., Eremina, E., Rupp, D., Adolph, M., Thomas, H., Hoener, M., de Castro, A. R. B., Tiggesbäumker, J., Meiwes-Broer, K.-H., Laarmann, T., Wabnitz, H., Plönjes, E., Treusch, R., Schneider, J. R. \& Möller, T. (2012). Phys. Rev. Lett. 108, 093401.
Boutet, S., Lomb, L., Williams, G. J., Barends, T. R. M., Aquila, A., Doak, R. B., Weierstall, U., DePonte, D. P., Steinbrener, J., Shoeman, R. L., Messerschmidt, M., Barty, A., White, T. A., Kassemeyer, S., Kirian, R. A., Seibert, M. M., Montanez, P. A., Kenney, C., Herbst, R., Hart, P., Pines, J., Haller, G., Gruner, S. M., Philipp, H. T., Tate, M. W., Hromalik, M., Koerner, L. J., van Bakel, N., Morse, J., Ghonsalves, W., Arnlund, D., Bogan, M. J., Caleman, C., Fromme, R., Hampton, C. Y., Hunter, M. S., Johansson, L. C., Katona, G., Kupitz, C., Liang, M., Martin, A. V., Nass, K., Redecke, L., Stellato, F., Timneanu, N., Wang, D., Zatsepin, N. A., Schafer, D., Defever, J., Neutze, R., Fromme, P., Spence, J. C. H., Chapman, H. N. \& Schlichting, I. (2012). Science, 337, 362-364.

Bradski, G. (2000). Dr Dobb's Journal of Software Tools, http:// drdobbs.com/opensource/184404319.

Brus, L. E. (1984). J. Chem. Phys. 80, 4403-4409.

Burda, C., Chen, X., Narayanan, R. \& El-Sayed, M. A. (2005). Chem. Rev. 105, 1025-1102.

Chapman, H. N., Fromme, P., Barty, A., White, T. A., Kirian, R. A., Aquila, A., Hunter, M. S., Schulz, J., DePonte, D. P., Weierstall, U., Doak, R. B., Maia, F. R. N. C., Martin, A. V., Schlichting, I., Lomb, L., Coppola, N., Shoeman, R. L., Epp, S. W., Hartmann, R., Rolles, D., Rudenko, A., Foucar, L., Kimmel, N., Weidenspointner, G., Holl, P., Liang, M., Barthelmess, M., Caleman, C., Boutet, S., Bogan, M. J., Krzywinski, J., Bostedt, C., Bajt, S., Gumprecht, L., Rudek, B., Erk, B., Schmidt, C., Hömke, A., Reich, C., Pietschner, D., Strüder, L., Hauser, G., Gorke, H., Ullrich, J., Herrmann, S., Schaller, G., Schopper, F., Soltau, H., Kühnel, K.-U., Messerschmidt, M., Bozek, J. D., Hau-Riege, S. P., Frank, M., Hampton, C. Y., Sierra, R. G., Starodub, D., Williams, G. J., Hajdu, J., Timneanu, N., Seibert, M. M., Andreasson, J., Rocker, A., Jönsson, O., Svenda, M., Stern, S., Nass, K., Andritschke, R., Schröter, C.-D., Krasniqi, F., Bott, M., Schmidt, K. E., Wang, X., Grotjohann, I., Holton, J. M., Barends, T. R. M., Neutze, R., Marchesini, S., Fromme, R., Schorb, S., Rupp, D., Adolph, M., Gorkhover, T., Andersson, I., Hirsemann, H., Potdevin, G., Graafsma, H., Nilsson, B. \& Spence, J. C. H. (2011). Nature, 470, 73-77.

Chen, G., Modestino, M. A., Poon, B. K., Schirotzek, A., Marchesini, S., Segalman, R. A., Hexemer, A. \& Zwart, P. H. (2012). J. Synchrotron Rad. 19, 695-700.

Clark, J. N., Beitra, L., Xiong, G., Higginbotham, A., Fritz, D. M., Lemke, H. T., Zhu, D., Chollet, M., Williams, G. J., Messerschmidt, M., Abbey, B., Harder, R. J., Korsunsky, A. M., Wark, J. S. \& Robinson, I. K. (2013). Science, 341, 56-59.

Danylchenko, O. G., Kovalenko, S. I. \& Samovarov, V. N. (2004). Low Temp. Phys. 30, 166-170.

Ekeberg, T., Svenda, M., Abergel, C., Maia, F. R. N. C., Seltzer, V., Claverie, J.-M., Hantke, M., Jönsson, O., Nettelblad, C., van der Schot, G., Liang, M., DePonte, D. P., Barty, A., Seibert, M. M., Iwan, B., Andersson, I., Loh, N. D., Martin, A. V., Chapman, H., Bostedt, C., Bozek, J. D., Ferguson, K. R., Krzywinski, J., Epp, S. W., Rolles, D., Rudenko, A., Hartmann, R., Kimmel, N. \& Hajdu, J. (2015). Phys. Rev. Lett. 114, 098102.

Emma, P., Akre, R., Arthur, J., Bionta, R., Bostedt, C., Bozek, J., Brachmann, A., Bucksbaum, P., Coffee, R., Decker, F.-J., Ding, Y., Dowell, D., Edstrom, S., Fisher, A., Frisch, J., Gilevich, S., Hastings, J., Hays, G., Hering, Ph., Huang, Z., Iverson, R., Loos, H., Messerschmidt, M., Miahnahri, A., Moeller, S., Nuhn, H.-D., Pile, G., Ratner, D., Rzepiela, J., Schultz, D., Smith, T., Stefan, P., Tompkins, H., Turner, J., Welch, J., White, W., Wu, J., Yocky, G. \& Galayda, J. (2010). Nat. Photonics, 4, 641-647.

Farges, J., de Feraudy, M. F., Raoult, B. \& Torchet, G. (1983). J. Chem. Phys. 78, 5067-5080.

Ferguson, K. R. (2016). PhD thesis, Stanford University.

Ferguson, K. R., Bucher, M., Gorkhover, T., Boutet, S., Fukuzawa, H., Koglin, J. E., Kumagai, Y., Lutman, A., Marinelli, A., Messerschmidt, M., Nagaya, K., Turner, J., Ueda, K., Williams, G. J., Bucksbaum, P. H. \& Bostedt, C. (2016). Sci. Adv. 2, e1500837. 
Gomez, L. F., Ferguson, K. R., Cryan, J. P., Bacellar, C., Tanyag, R. M. P., Jones, C., Schorb, S., Anielski, D., Belkacem, A., Bernando, C., Boll, R., Bozek, J., Carron, S., Chen, G., Delmas, T., Englert, L., Epp, S. W., Erk, B., Foucar, L., Hartmann, R., Hexemer, A., Huth, M., Kwok, J., Leone, S. R., Ma, J. H. S., Maia, F. R. N. C., Malmerberg, E., Marchesini, S., Neumark, D. M., Poon, B., Prell, J., Rolles, D., Rudek, B., Rudenko, A., Seifrid, M., Siefermann, K. R., Sturm, F. P., Swiggers, M., Ullrich, J., Weise, F., Zwart, P., Bostedt, C., Gessner, O. \& Vilesov, A. F. (2014). Science, 345, 906-909.

Gorkhover, T., Adolph, M., Rupp, D., Schorb, S., Epp, S. W., Erk, B., Foucar, L., Hartmann, R., Kimmel, N., Kühnel, K.-U., Rolles, D., Rudek, B., Rudenko, A., Andritschke, R., Aquila, A., Bozek, J. D., Coppola, N., Erke, T., Filsinger, F., Gorke, H., Graafsma, H., Gumprecht, L., Hauser, G., Herrmann, S., Hirsemann, H., Hömke, A., Holl, P., Kaiser, C., Krasniqi, F., Meyer, J.-H., Matysek, M., Messerschmidt, M., Miessner, D., Nilsson, B., Pietschner, D., Potdevin, G., Reich, C., Schaller, G., Schmidt, C., Schopper, F., Schröter, C. D., Schulz, J., Soltau, H., Weidenspointner, G., Schlichting, I., Strüder, L., Ullrich, J., Möller, T. \& Bostedt, C. (2012). Phys. Rev. Lett. 108, 245005.

Hagena, O. F. (1981). Surf. Sci. 106, 101-116.

Halperin, W. P. (1986). Rev. Mod. Phys. 58, 533-606.

Hantke, M. F., Hasse, D., Maia, F. R. N. C., Ekeberg, T., John, K., Svenda, M., Loh, N. D., Martin, A. V., Timneanu, N., Larsson, D. S. D., van der Schot, G., Carlsson, G. H., Ingelman, M., Andreasson, J., Westphal, D., Liang, M., Stellato, F., DePonte, D. P., Hartmann, R., Kimmel, N., Kirian, R. A., Seibert, M. M., Mühlig, K., Schorb, S., Ferguson, K., Bostedt, C., Carron, S., Bozek, J. D., Rolles, D., Rudenko, A., Epp, S., Chapman, H. N., Barty, A., Hajdu, J. \& Andersson, I. (2014). Nat. Photonics, 8, 943-949.

Inubushi, Y., Tono, K., Togashi, T., Sato, T., Hatsui, T., Kameshima, T., Togawa, K., Hara, T., Tanaka, T., Tanaka, H., Ishikawa, T. \& Yabashi, M. (2012). Phys. Rev. Lett. 109, 144801.

Ishikawa, T., Aoyagi, H., Asaka, T., Asano, Y., Azumi, N., Bizen, T., Ego, H., Fukami, K., Fukui, T., Furukawa, Y., Goto, S., Hanaki, H., Hara, T., Hasegawa, T., Hatsui, T., Higashiya, A., Hirono, T., Hosoda, N., Ishii, M., Inagaki, T., Inubushi, Y., Itoga, T., Joti, Y., Kago, M., Kameshima, T., Kimura, H., Kirihara, Y., Kiyomichi, A., Kobayashi, T., Kondo, C., Kudo, T., Maesaka, H., Maréchal, X. M., Masuda, T., Matsubara, S., Matsumoto, T., Matsushita, T., Matsui, S., Nagasono, M., Nariyama, N., Ohashi, H., Ohata, T., Ohshima, T., Ono, S., Otake, Y., Saji, C., Sakurai, T., Sato, T., Sawada, K., Seike, T., Shirasawa, K., Sugimoto, T., Suzuki, S., Takahashi, S., Takebe, H., Takeshita, K., Tamasaku, K., Tanaka, H., Tanaka, R., Tanaka, T., Togashi, T., Togawa, K., Tokuhisa, A., Tomizawa, H., Tono, K., Wu, S., Yabashi, M., Yamaga, M., Yamashita, A., Yanagida, K., Zhang, C., Shintake, T., Kitamura, H. \& Kumagai, N. (2012). Nat. Photonics, 6, 540-544.

Kam, Z. (1977). Macromolecules, 10, 927-934.

Kam, Z. (1980). J. Theor. Biol. 82, 15-39.

Kam, Z., Koch, M. H. \& Bordas, J. (1981). Proc. Natl Acad. Sci. 78, 3559-3562.

Kameshima, T., Ono, S., Kudo, T., Ozaki, K., Kirihara, Y., Kobayashi, K., Inubushi, Y., Yabashi, M., Horigome, T., Holland, A., Holland, K., Burt, D., Murao, H. \& Hatsui, T. (2014). Rev. Sci. Instrum. 85, 033110.

Katayama, T., Hirano, T., Morioka, Y., Sano, Y., Osaka, T., Owada, S., Togashi, T. \& Yabashi, M. (2019). J. Synchrotron Rad. 26, 333-338.

Kittel, C. (2004). Introduction to Solid State Physics. 8th ed. John Wiley \& Sons.

Ko, I. S., Kang, H.-S., Heo, H., Kim, C., Kim, G., Min, C.-K., Yang, H., Baek, S. Y., Choi, H.-J., Mun, G., Park, B. R., Suh, Y. J., Shin, D. C., Hu, J., Hong, J., Jung, S., Kim, S.-H., Kim, K., Na, D., Park, S. S., Park, Y. J., Jung, Y. G., Jeong, S. H., Lee, H. G., Lee, S., Lee, S., Oh, B., Suh, H. S., Han, J.-H., Kim, M. H., Jung, N.-S., Kim, Y.-C., Lee, M.-S., Lee, B.-H., Sung, C.-W., Mok, I.-S., Yang, J.-M., Parc, Y. W., Lee, W.-W., Lee, C.-S., Shin, H., Kim, J. H., Kim, Y., Lee, J. H., Park, S.-Y., Kim, J., Park, J., Eom, I., Rah, S., Kim, S., Nam, K. H., Park, J.,
Park, J., Kim, S., Kwon, S., An, R., Park, S. H., Kim, K. S., Hyun, H., Kim, S. N., Kim, S., Yu, C.-J., Kim, B.-S., Kang, T.-H., Kim, K.-W., Kim, S.-H., Lee, H.-S., Lee, H.-S., Park, K.-H., Koo, T.-Y., Kim, D.E. \& Lee, K. B. (2017). Appl. Sci. 7, 479.

Kupitz, C., Basu, S., Grotjohann, I., Fromme, R., Zatsepin, N. A., Rendek, K. N., Hunter, M. S., Shoeman, R. L., White, T. A., Wang, D., James, D., Yang, J.-H., Cobb, D. E., Reeder, B., Sierra, R. G., Liu, H., Barty, A., Aquila, A. L., Deponte, D., Kirian, R. A., Bari, S., Bergkamp, J. J., Beyerlein, K. R., Bogan, M. J., Caleman, C., Chao, T.-C. C., Conrad, C. E., Davis, K. M., Fleckenstein, H., Galli, L., Hau-Riege, S. P., Kassemeyer, S., Laksmono, H., Liang, M., Lomb, L., Marchesini, S., Martin, A. V., Messerschmidt, M., Milathianaki, D., Nass, K., Ros, A., Roy-Chowdhury, S., Schmidt, K., Seibert, M., Steinbrener, J., Stellato, F., Yan, L., Yoon, C., Moore, T. A., Moore, A. L., Pushkar, Y., Williams, G. J., Boutet, S., Doak, R. B., Weierstall, U., Frank, M., Chapman, H. N., Spence, J. C. H. \& Fromme, P. (2014). Nature, 513, 261-265.

Kurta, R. P., Donatelli, J. J., Yoon, C. H., Berntsen, P., Bielecki, J., Daurer, B. J., DeMirci, H., Fromme, P., Hantke, M. F., Maia, F. R. N. C., Munke, A., Nettelblad, C., Pande, K., Reddy, H. K. N., Sellberg, J. A., Sierra, R. G., Svenda, M., van der Schot, G., Vartanyants, I. A., Williams, G. J., Xavier, P. L., Aquila, A., Zwart, P. H. \& Mancuso, A. P. (2017). Phys. Rev. Lett. 119, 158102.

Liu, H., Poon, B. K., Saldin, D. K., Spence, J. C. H. \& Zwart, P. H. (2013). Acta Cryst. A69, 365-373.

Loh, N. D., Hampton, C. Y., Martin, A. V., Starodub, D., Sierra, R. G., Barty, A., Aquila, A., Schulz, J., Lomb, L., Steinbrener, J., Shoeman, R. L., Kassemeyer, S., Bostedt, C., Bozek, J., Epp, S. W., Erk, B., Hartmann, R., Rolles, D., Rudenko, A., Rudek, B., Foucar, L., Kimmel, N., Weidenspointner, G., Hauser, G., Holl, P., Pedersoli, E., Liang, M., Hunter, M. S., Gumprecht, L., Coppola, N., Wunderer, C., Graafsma, H., Maia, F. R., Ekeberg, T., Hantke, M., Fleckenstein, H., Hirsemann, H., Nass, K., White, T. A., Tobias, H. J., Farquar, G. R., Benner, W. H., Hau-Riege, S. P., Reich, C., Hartmann, A., Soltau, H., Marchesini, S., Bajt, S., Barthelmess, M., Bucksbaum, P., Hodgson, K. O., Strüder, L., Ullrich, J., Frank, M., Schlichting, I., Chapman, H. N. \& Bogan, M. J. (2012). Nature, 486, 513-517.

Malmerberg, E., Kerfeld, C. A. \& Zwart, P. H. (2015). IUCrJ, 2, 309316.

Mendez, D., Lane, T. J., Sung, J., Sellberg, J., Levard, C., Watkins, H., Cohen, A. E., Soltis, M., Sutton, S., Spudich, J., Pande, V., Ratner, D. \& Doniach, S. (2014). Phil. Trans. R. Soc. B, 369, 20130315.

Mendez, D., Watkins, H., Qiao, S., Raines, K. S., Lane, T. J., Schenk, G., Nelson, G., Subramanian, G., Tono, K., Joti, Y., Yabashi, M., Ratner, D. \& Doniach, S. (2016). IUCrJ, 3, 420-429.

Milne, C. J., Schietinger, T., Aiba, M., Alarcon, A., Alex, J., Anghel, A., Arsov, V., Beard, C., Beaud, P., Bettoni, S., Bopp, M., Brands, H., Brönnimann, M., Brunnenkant, I., Calvi, M., Citterio, A., Craievich, P., Csatari Divall, M., Dällenbach, M., D'Amico, M., Dax, A., Deng, Y., Dietrich, A., Dinapoli, R., Divall, E., Dordevic, S., Ebner, S., Erny, C., Fitze, H., Flechsig, U., Follath, R., Frei, F., Gärtner, F., Ganter, R., Garvey, T., Geng, Z., Gorgisyan, I., Gough, C., Hauff, A., Hauri, C. H., Hiller, N., Humar, T., Hunziker, S., Ingold, G., Ischebeck, R., Janousch, M., Juranić, P., Jurcevic, M., Kaiser, M., Kalantari, B., Kalt, R., Keil, B., Kittel, C., Knopp, G., Koprek, W., Lemke, H. T., Lippuner, T., Llorente Sancho, D., Löhl, F., Lopez-Cuenca, C., Märki, F., Marcellini, F., Marinkovic, G., Martiel, I., Menzel, R., Mozzanica, A., Nass, K., Orlandi, G. L., Ozkan Loch, C., Panepucci, E., Paraliev, M., Patterson, B., Pedrini, B., Pedrozzi, M., Pollet, P., Pradervand, C., Prat, E., Radi, P., Raguin, J.-Y., Redford, S., Rehanek, J., Réhault, J., Reiche, S., Ringele, M., Rittmann, J., Rivkin, L., Romann, A., Ruat, M., Ruder, C., Sala, L., Schebacher, L., Schilcher, T., Schlott, V., Schmidt, T., Schmitt, B., Shi, X., Stadler, M., Stingelin, L., Sturzenegger, W., Szlachetko, J., Thattil, D., Treyer, D. M., Trisorio, A., Tron, W., Vetter, S., Vicario, C., Voulot, D., Wang, M., Zamofing, T., 
Zellweger, C., Zennaro, R., Zimoch, E., Abela, R., Patthey, L. \& Braun, H.-H. (2017). Appl. Sci. 7, 720.

Nishiyama, T., Kumagai, Y., Niozu, A., Fukuzawa, H., Motomura, K., Bucher, M., Ito, Y., Takanashi, T., Asa, K., Sato, Y., You, D., Li, Y., Ono, T., Kukk, E., Miron, C., Neagu, L., Callegari, C., Di Fraia, M., Rossi, G., Galli, D. E., Pincelli, T., Colombo, A., Kameshima, T., Joti, Y., Hatsui, T., Owada, S., Katayama, T., Togashi, T., Tono, K., Yabashi, M., Matsuda, K., Bostedt, C., Nagaya, K. \& Ueda, K. (2019). Phys. Rev. Lett. 123, 123201.

Paterson, M. S. (1952). J. Appl. Phys. 23, 805-811.

Redecke, L., Nass, K., DePonte, D. P., White, T. A., Rehders, D., Barty, A., Stellato, F., Liang, M., Barends, T. R. M., Boutet, S., Williams, G. J., Messerschmidt, M., Seibert, M. M., Aquila, A., Arnlund, D., Bajt, S., Barth, T., Bogan, M. J., Caleman, C., Chao, T.C., Doak, R. B., Fleckenstein, H., Frank, M., Fromme, R., Galli, L., Grotjohann, I., Hunter, M. S., Johansson, L. C., Kassemeyer, S., Katona, G., Kirian, R. A., Koopmann, R., Kupitz, C., Lomb, L., Martin, A. V., Mogk, S., Neutze, R., Shoeman, R. L., Steinbrener, J., Timneanu, N., Wang, D., Weierstall, U., Zatsepin, N. A., Spence, J. C. H., Fromme, P., Schlichting, I., Duszenko, M., Betzel, C. \& Chapman, H. N. (2013). Science, 339, 227-230.

Rose, M., Bobkov, S., Ayyer, K., Kurta, R. P., Dzhigaev, D., Kim, Y. Y., Morgan, A. J., Yoon, C. H., Westphal, D., Bielecki, J., Sellberg, J. A., Williams, G., Maia, F. R. N. C., Yefanov, O. M., Ilyin, V., Mancuso, A. P., Chapman, H. N., Hogue, B. G., Aquila, A., Barty, A. \& Vartanyants, I. A. (2018). IUCrJ, 5, 727-736.

Seibert, M. M., Ekeberg, T., Maia, F. R. N. C., Svenda, M., Andreasson, J., Jönsson, O., Odić, D., Iwan, B., Rocker, A., Westphal, D., Hantke, M., DePonte, D. P., Barty, A., Schulz, J., Gumprecht, L., Coppola, N., Aquila, A., Liang, M., White, T. A., Martin, A., Caleman, C., Stern, S., Abergel, C., Seltzer, V., Claverie, J.-M., Bostedt, C., Bozek, J. D., Boutet, S., Miahnahri, A. A., Messerschmidt, M., Krzywinski, J., Williams, G., Hodgson, K. O., Bogan, M. J., Hampton, C. Y., Sierra, R. G., Starodub, D., Andersson, I., Bajt, S., Barthelmess, M., Spence, J. C. H., Fromme, P., Weierstall, U., Kirian, R., Hunter, M., Doak, R. B., Marchesini, S., Hau-Riege, S. P., Frank, M., Shoeman, R. L.,
Lomb, L., Epp, S. W., Hartmann, R., Rolles, D., Rudenko, A., Schmidt, C., Foucar, L., Kimmel, N., Holl, P., Rudek, B., Erk, B., Hömke, A., Reich, C., Pietschner, D., Weidenspointner, G., Strüder, L., Hauser, G., Gorke, H., Ullrich, J., Schlichting, I., Herrmann, S., Schaller, G., Schopper, F., Soltau, H., Kühnel, K.U., Andritschke, R., Schröter, C.-D., Krasniqi, F., Bott, M., Schorb, S., Rupp, D., Adolph, M., Gorkhover, T., Hirsemann, H., Potdevin, G., Graafsma, H., Nilsson, B., Chapman, H. N. \& Hajdu, J. (2011). Nature, 470, 78-81.

Starodub, D., Aquila, A., Bajt, S., Barthelmess, M., Barty, A., Bostedt, C., Bozek, J. D., Coppola, N., Doak, R. B., Epp, S. W., Erk, B., Foucar, L., Gumprecht, L., Hampton, C. Y., Hartmann, A., Hartmann, R., Holl, P., Kassemeyer, S., Kimmel, N., Laksmono, H., Liang, M., Loh, N. D., Lomb, L., Martin, A. V., Nass, K., Reich, C., Rolles, D., Rudek, B., Rudenko, A., Schulz, J., Shoeman, R. L., Sierra, R. G., Soltau, H., Steinbrener, J., Stellato, F., Stern, S., Weidenspointner, G., Frank, M., Ullrich, J., Strüder, L., Schlichting, I., Chapman, H. N., Spence, J. C. H. \& Bogan, M. J. (2012). Nat. Commun. 3, 1276.

Takahashi, Y., Suzuki, A., Zettsu, N., Oroguchi, T., Takayama, Y., Sekiguchi, Y., Kobayashi, A., Yamamoto, M. \& Nakasako, M. (2013). Nano Lett. 13, 6028-6032.

Tschentscher, T., Bressler, C., Grünert, J., Madsen, A., Mancuso, A. P., Meyer, M., Scherz, A., Sinn, H. \& Zastrau, U. (2017). Appl. Sci. 7, 592.

Waal, B. W. van de, Torchet, G. \& de Feraudy, M.-F. (2000). Chem. Phys. Lett. 331, 57-63.

Xu, R., Jiang, H., Song, C., Rodriguez, J. A., Huang, Z., Chen, C.-C., Nam, D., Park, J., Gallagher-Jones, M., Kim, S., Kim, S., Suzuki, A., Takayama, Y., Oroguchi, T., Takahashi, Y., Fan, J., Zou, Y., Hatsui, T., Inubushi, Y., Kameshima, T., Yonekura, K., Tono, K., Togashi, T., Sato, T., Yamamoto, M., Nakasako, M., Yabashi, M., Ishikawa, T. \& Miao, J. (2014). Nat. Commun. 5, 4061.

Yabashi, M., Tanaka, H., Tono, K. \& Ishikawa, T. (2017). Appl. Sci. 7, 604.

Zaluzhnyy, I. A., Kurta, R. P., Scheele, M., Schreiber, F., Ostrovskii, B. \& Vartanyants, I. A.(2019). Materials, 12, 3464. 